\title{
Construction of a multiple fluorescence labelling system for use in co-invasion studies of Listeria monocytogenes Jens B Andersen ${ }^{1}$, Bent B Roldgaard ${ }^{1}$, Ariel B Lindner ${ }^{2}$, Bjarke B Christensen ${ }^{1}$ and Tine R Licht* 1
}

Address: ${ }^{1}$ Danish Institute for Food and Veterinary Research, Department of Microbiological Food Safety, Mørkhøj Bygade 19, 2860 Søborg, Denmark and ${ }^{2}$ Molecular, Evolution and Medical Genetics Laboratory, INSERM U571, Necker-Enfants Malades Faculty of Medicine, René Decartes - Paris V University, 156 Rue de Vaugirard, 75730 Paris Cedex 15, France

Email: Jens B Andersen - jeban@dfvf.dk; Bent B Roldgaard - bebro@dfvf.dk; Ariel B Lindner - lindner@necker.fr; Bjarke B Christensen - bbc@dfvf.dk; Tine R Licht* - trl@dfvf.dk

* Corresponding author

Published: 03 October 2006

BMC Microbiology 2006, 6:86 doi:10.1/86/147|-2180-6-86
Received: 18 July 2006

Accepted: 03 October 2006

This article is available from: http://www.biomedcentral.com/I47I-2/80/6/86

(c) 2006 Andersen et al; licensee BioMed Central Ltd.

This is an Open Access article distributed under the terms of the Creative Commons Attribution License (http://creativecommons.org/licenses/by/2.0), which permits unrestricted use, distribution, and reproduction in any medium, provided the original work is properly cited.

\begin{abstract}
Background: Existing virulence models are often difficult to apply for quantitative comparison of invasion potentials of Listeria monocytogenes. Well-to-well variation between cell-line based in vitro assays is practically unavoidable, and variation between individual animals is the cause of large deviations in the observed capacity for infection when animal models are used.
\end{abstract}

One way to circumvent this problem is to carry out virulence studies as competition assays between 2 or more strains. This, however, requires invasion-neutral markers that enable easy discrimination between the different strains.

Results: A fluorescent marker system, allowing visualization and identification of single $L$. monocytogenes cells as well as colonies in a non-destructive manner, was developed. Five different fluorescent labels are available, and allowed simultaneous visual discrimination between three differently labelled strains at the single cell level by use of fluorescence microscopy. More than $90 \%$ of the $L$. monocytogenes host cells maintained the fluorescence tags for $\mathbf{4 0}$ generations.

The fluorescence tags did not alter the invasive capacity of the $L$. monocytogenes cells in a traditional Caco-2 cell invasion assay, and visual discrimination between invaded bacteria carrying different fluorescent labels inside the cells was possible.

Conclusion: The constructed fluorescent marker system is stable, easy to use, does not affect the virulence of $L$. monocytogenes in Caco-2 cell assays, and allows discrimination between differently labelled bacteria after internalization in these cells.

\section{Background}

Listeria monocytogenes is an intracellular pathogen of humans and animals [1], and has been implicated in several foodborne outbreaks as well as sporadic cases of disease during the last ten to fifteen years [2]. It is known that differences between strains as well as differences in environmental conditions affect the invasive potential of this pathogen [3-5]. Virulence models allowing comparison of the pathogenic potency of different cultures of Listeria are therefore essential tools in the study of bacteria within 
this genus. Additionally, such models are needed to study the role of specific genes in the process of infection.

Virulence models most commonly applied include cellline based assays and various animal models. However, a number of obstacles are associated with the use of such models for comparative studies of the infectivity of Listeria. Despite efforts to optimize reproducibility in cell line based in vitro studies, well to well variation is difficult to avoid [6]. Likewise, in animal models, regardless of the employment of well-characterised laboratory animal strains, variations between individual animals commonly occur. The lack of accurate reproducibility in existing virulence models means that it is often difficult to compare the virulence of two different Listeria strains in a quantitative manner. A solution to this problem is to carry out virulence studies as competition assays between two or more strains. This approach has been applied with success by use of Listeria carrying resistance markers to various antibiotics [7]. An attractive alternative is to use fluorescent protein markers. The Green Fluorescent Protein (GFP) was introduced approximately ten years ago as a convenient tool for studies of the pathogenesis of e.g. Salmonella typhimurium and Yersenia paratuberculosis [8]. More recently, this protein has been applied in studies of Grampositive bacteria including Streptococcus suis [9], and Listeria monocytogenes $[10,11]$. The advantage of fluorescent markers, when compared to resistance gene markers, is that they allow direct visualization and real-time studies of tagged bacteria. Furthermore, they allow certain identification of the tagged strains in un-sterile systems such as the mammalian gastrointestinal tract, where naturally occurring resistant bacteria may be difficult to distinguish from resistance-tagged strains. The disadvantage of fluorescence tagging is that small, tagged subpopulations can be difficult to quantify, since selection for fluorescence is not possible. This disadvantage may be overcome by combining fluorescent markers with antibiotic resistance markers.

We have developed a fluorescent marker system that allows identification of single Listeria cells as well as colonies in a non-destructive manner, and demonstrate its use in a traditional Caco- 2 cell invasion assay.

\section{Results and discussion}

A multicolour tagging system based on the synthesis of Cyan Fluorescent Protein (CFP), Green Fluorescent Protein (GFP), Yellow Fluorescent Protein (YFP), DsRedExpress or HcRed

Fluorescent microscopy at $16 \times$ magnification revealed that L. monocytogenes ScottA harbouring either pNF8 (wtGFP), pJEBAN2 (wt-CFP), pJEBAN3 (wt-YFP), pJEBAN4 (wt-HcRed) and pJEBAN6 (wt-DsRedEx) all gave rise to easily detectable fluorescent colonies of the expected col- our, demonstrating that a heterolog expression of Green Fluorescent Protein (GFP), Cyan Fluorescent Protein (CFP), Yellow Fluorescent Protein (YFP), or the red fluorescent markers HcRed and DsRedexpress had successfully been established in L. monocytogenes ScottA. The labelling system was tested and shown to confer the expected fluorescence also to other strains of $L$. monocytogenes, including EGDe and LO28 (Table 1).

L. monocytogenes cells tagged with any of the fluorescent proteins could be detected at the single cell level by fluorescence microscopy (630× magnification). By employment of appropriate combinations of different excitation wavelength and different filtersets, spectral discrimination between strains wt-CFP, wt-YFP and wt-DsRedEx mixed in a ratio of 1:1:1 was obtained at the single cell level (Figure 1). Although CFP, YFP and DsRedExpress are not maximally excitated by UV-light, visual inspection revealed that colonies of wt-CFP, wt-YFP and wt-DsRedEx could be discriminated when placed on a $302 \mathrm{nmUV}$-table (Figure 2). GFP tagged Listeria also gave rise to fluorescent colonies when excitated at $302 \mathrm{~nm}$, however as expected from the similar spectral properties of GFP (emission maximum at $510 \mathrm{~nm}$ ), and YFP (emission maximum at 527 $\mathrm{nm}$ ), visual differentiation between GFP-tagged and YFPtagged L. monocytogenes at the colony level was not possible. Similarly, visual discrimination between colonies of GFP- and CFP-tagged cells was difficult.

\section{Listerial growth and plasmid stability in batch cultures}

No difference in growth rate between the labelled strains was observed during exponential growth in Erythromycin-supplemented BHI of L. monocytogenes ScottA tagged with plasmids carrying CFP, GFP, YFP, DsRedEx or HcRed. This observation is important for the utility of the tagged stains in comparative co-inoculation studies, where biases in growth could obscure the results.

Propagation of the five labelled strains for 100 generations without Erythromycin revealed that within the first 40 generations, more than $90 \%$ of the bacteria in any of the five cultures still carried the plasmid. No significant differences in the fraction of plasmid harbouring cells were observed among the five cultures during this period, clearly demonstration that the segregational stability of pNF8, pJEBAN2, pJEBAN3, pJEBAN4 and pJEBAN6 was the same for all plasmids during the first 40 generations (Figure 3). Throughout the experiment, the fraction of plasmid harbouring bacteria as a function of the number of cell divisions was similar for cultures of L. monocytogenes tagged with CFP, GFP, and YFP, reaching a value of approximately $20 \%$ following propagation for 100 generations in the absence of selective pressure. Likewise, the fraction of plasmid harbouring bacteria as a function of generation number was observed to be similar in cultures 
Table I: Strains and plasmids

\begin{tabular}{|c|c|c|}
\hline Strains & Relevant genotype and characteristics & Reference \\
\hline \multicolumn{3}{|c|}{ 舟 } \\
\hline SI7-I $\lambda$ pir & 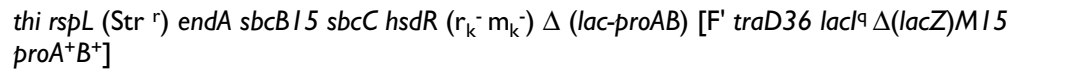 & {$[26]$} \\
\hline JMI05 & 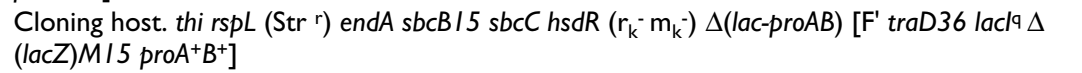 & {$[27]$} \\
\hline L. monocytogenes EGDe & Host strain & [28] \\
\hline L. monocytogenes LO28 & Host strain & [29] \\
\hline L. monocytogenes ScottA & Host strain & {$[30]$} \\
\hline Wt & $\mathrm{Nal}{ }^{R}$ mutant of L. monocytogenes ScottA (wt) & \\
\hline inl $A^{\prime}$ & $\begin{array}{l}\mathrm{Nal} \text {; inlA mutant of } L \text {. monocytogenes ScottA (wt) carrying an inframe deletion of the last } 800 \\
\text { bp of the inlA gene. }\end{array}$ & This study \\
\hline wt-CFP & Nal ${ }^{R} ; m^{R} ;(S \operatorname{cottA} w t)$ harbouring pJEBAN2 & This study \\
\hline wt-GFP & NalR; Em²; (wt) harbouring pNF8 & This study \\
\hline wt-YFP & NalR; Em²; (ScottA wt) harbouring pJEBAN3 & This study \\
\hline wt-HcRed & NalR; Em ${ }^{R}$ (ScottA wt) harbouring pJEBAN4 & This study \\
\hline wt-DsRed & NalR; Em²; (ScottA wt) harbouring pJEBAN6 & This study \\
\hline inIA'-CFP & 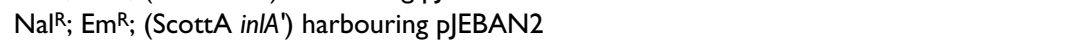 & This study \\
\hline inlA'-YFP & NalR; Em ${ }^{R} ;(S \operatorname{cott} A$ inlA') harbouring PJEBAN3 & This study \\
\hline \multicolumn{3}{|l|}{ Plasmids } \\
\hline pUC-cfp ${ }^{++}$ & $A p^{R}$; donor of $c f p^{++}$gene & This study \\
\hline pUC-yfp ${ }^{++}$ & $A p^{R}$; donor of $y \mathrm{fp}^{++}$gene & This study \\
\hline PhcRedl & $A p^{R}$; donor of HcRed gene & Clontech laboratories Inc. \\
\hline PdsRed-Express & $A p^{R}$; donor of DsRed-Express gene & Clontech laboratories Inc. \\
\hline pNF8 & $\mathrm{Em}^{\mathrm{R}}, \mathrm{Mob}^{+}(\mathrm{IncP})$, oriR pAMßI, oriR pUC; Pdlt-gfpmutl & {$[10]$} \\
\hline PJEBAN2 & $\mathrm{Em}^{\mathrm{R}}, \mathrm{Mob}^{+}(\mathrm{IncP})$, oriR pAMßI, oriR pUC; Pdlt-cfp + & This study \\
\hline PJEBAN3 & $\mathrm{Em}^{\mathrm{R}}, \mathrm{Mob}^{+}(\mathrm{IncP})$, oriR pAM $\beta \mathrm{I}$, oriR pUC; Pdlt-yfp + & This study \\
\hline PJEBAN4 & $\mathrm{Em}^{\mathrm{R}}, \mathrm{Mob}^{+}($IncP), oriR pAMßI, oriR pUC; Pdlt-HcRed & This study \\
\hline PJEBAN6 & $\mathrm{Em}^{\mathrm{R}}, \mathrm{Mob}^{+}($IncP), oriR pAM $\beta \mathrm{I}$, oriR pUC; Pdlt-DsRedExpress & This study \\
\hline pAUL-A & $\mathrm{Em}^{\mathrm{R}}$ & [24] \\
\hline PJEBAN I 2 & $\begin{array}{l}E m^{R} \text {, pAUL-A carrying a } 538 \text { bp PCR product that give rise to an inframe deletion of the last } \\
77 \text { I bp of InlA when recombined into the chromosome of } L \text {. monocytogenes ScottA }\end{array}$ & This study \\
\hline
\end{tabular}

of HcRed- and DsRedEx-tagged cells, however more than $50 \%$ of these bacteria still carried the plasmid at the end of the experiment (Figure 3 ). This group of plasmids was thus slightly more stably maintained than the plasmids tagged with CFP, GFP and YFP, which are all derivatives of the same Green Fluorescent Protein isolated from the jellyfish Aequorea victoria $[10,12]$. The sequences of the red fluorescent proteins, which are obtained from the sea anemone Heteractis crispa [13] and the coral Discosoma [14], respectively, are shorter than the GFP-derived proteins, which may mean that they impose a smaller cell burden on the tagged Listeria, thus explaining the better stability. The observed differences in maintenance should be taken into consideration when applying the constructed plasmids (Table 1) for comparison experiments where fluorescence tagged bacteria are quantified after more than 40 bacterial generations.

Non-fluorescent, erythromycin resistant colonies were never observed in any of the 5 cultures investigated, con- firming that all the constructed plasmids were $100 \%$ structurally stable.

\section{Invasion assays with fluorescence-tagged bacteria}

Exposure of Caco-2 cells to the fluorescence tagged strains of $L$. monocytogenes ScottA at an infection multiplicity of approximately 25 bacteria per cell showed that infection potentials of these strains were not different $(p<0.05)$ from that of the un-tagged parent strain (Figure 4). Expression of the fluorescent proteins thus did not affect the infection potential of the investigated strain. Additionally, when wt strains with three different fluorescent tags were mixed in a ratio of 1:1:1 prior to invasion in Caco-2 cells, almost the same ratio was found between the tagged Listeria that had invaded the cells, showing that differently labelled strains were equally virulent (Figure 5). Caco-2 assays performed with the L. monocytogenes strains EGDe and LO28 tagged with either CFP or YFP showed that the invasion frequency was independent of these two fluorescent tags also in other strain backgrounds (data not shown). 


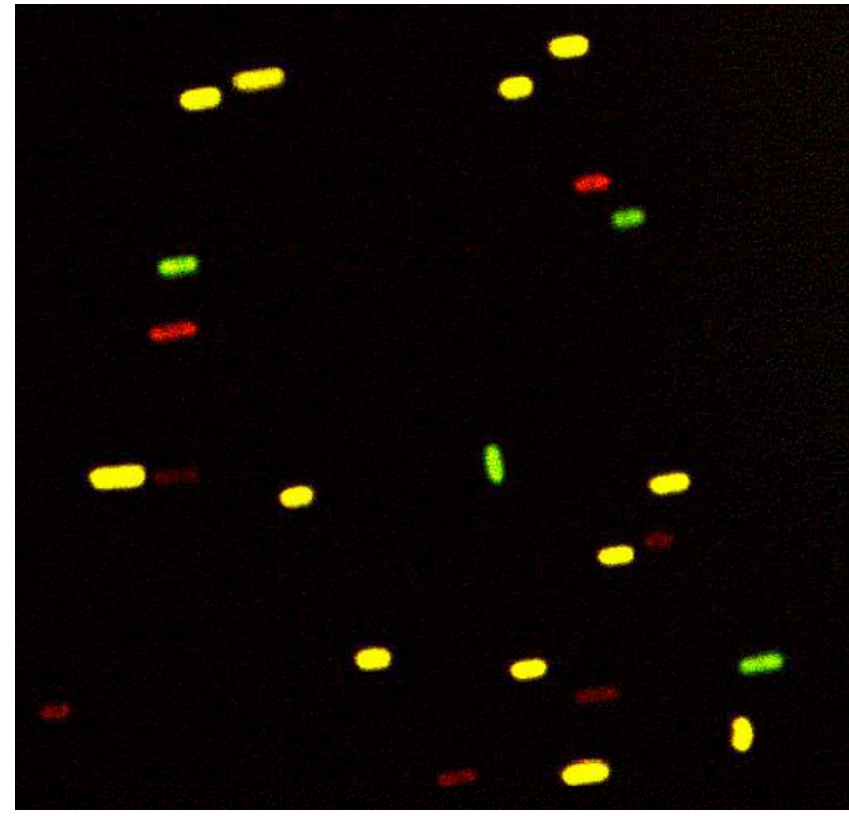

Figure I

Visualization of fluorescent $L$. monocytogenes cells. Confocal image showing single cells of $L$. monocytogenes tagged with CFP, YFP or DsREdExpress. Over night cultures of each of the three strains were mixed in a $1: 1: I$ ratio prior to visualization. Exitation wavelengths were 456,488 or 543 $\mathrm{nm}$, and emission was captured at 500-510, 555-583 or 592$640 \mathrm{~nm}$.

It should be noted, that infection of mammalian cells does not give full information about infection at the levels of complex tissues and individuals. However, unpublished data from our lab indicated that also in a guineapig model, the virulence of Listeria was unaffected by the fluorescent labels [B. B. Roldgaard, J. B. Andersen, T.R. Licht and B.B. Christensen, unpublished]. This is in accordance with previous studies showing that GFP-tagging did not affect the virulence of Listeria in a murine model [10].

An L. monocytogenes ScottA strain carrying a mutation in the inlA gene, encoding InternalinA which is known to be necessary for listerial epithelial invasion [15] was constructed and designated inlA'. The infection potential of the inlA' mutant was more than 1000 fold lower than observed for the wt strains (Figure 4), which is in accordance with previous reports $[16,17]$.

When fluorescence-tagged L. monocytogenes wt strains were mixed with the fluorescence-tagged invasionimpaired inlA' mutant, the difference in invasion capacity observed for the individual strains was reflected also in the mixed infections (Figure 5). However, since it was not possible to select for the mutant strain, the detection limit

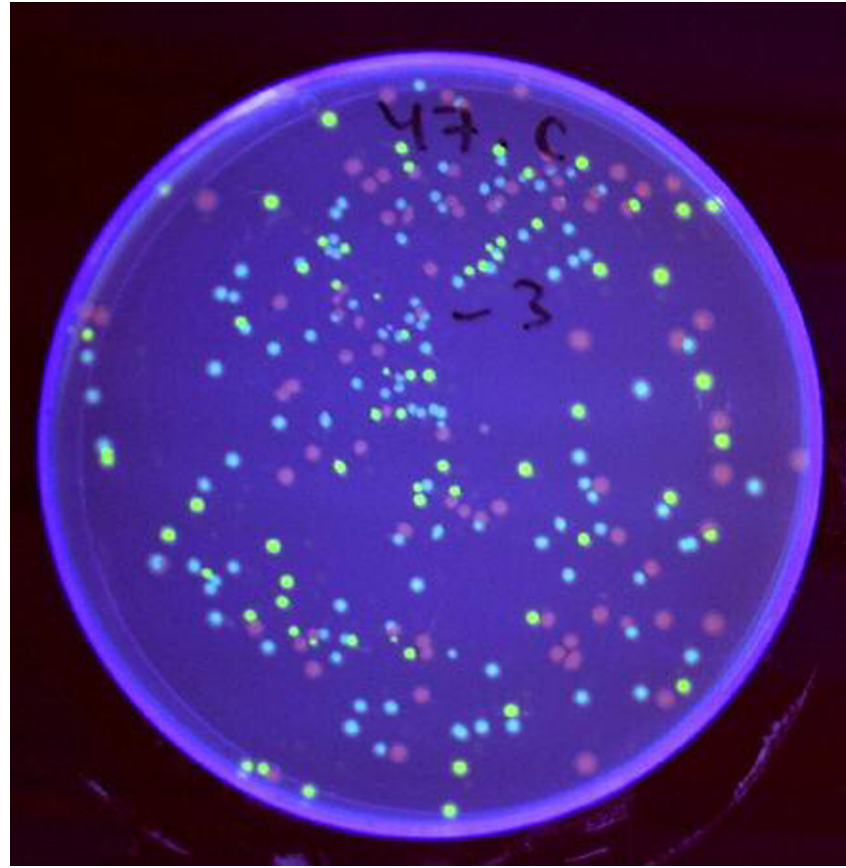

Figure 2

Visualization of fluorescent $L$. monocytogenes colonies. Colonies of wt-CFP, wt-YFP and wt-DsRedExpress could be discriminated when placed on a $302 \mathrm{nmUV}$-table, and appeared bluish, yellow and red.

was increased by the presence of the wt strain, which outnumbered the mutant about 1000 fold as expected from the separate invasion assays (Figure 4).

This demonstrates that co-invasion assays may be a useful method for rapid screening of differences in infection potentials between different strains of L. monocytogenes when a fluorescent labelling system is used for discrimination between the strains. Additionally, it shows that the presence of the wt strain does not mediate passive uptake of the inlA' mutant. Fluorescent bacteria were easily visualized and distinguished from each other inside the Caco2 cells by fluorescence microscopy (Figure 6).

\section{Conclusion}

We have developed a stable fluorescent labelling system for use in L. monocytogenes, and demonstrate that the labels do not affect the invasion potential of $L$. monocytogenes ScottA nor of an invasion-impaired mutant of this strain. The fluorescent labels allows easy discrimination between tagged cells and other bacteria in un-sterile systems, as well as discrimination between strains carrying different fluorescent markers, and provides a highly useful tool for researchers addressing virulence mechanisms of Listeria. Additionally, the labelling system allows realtime studies and visualization of bacteria internalized in 


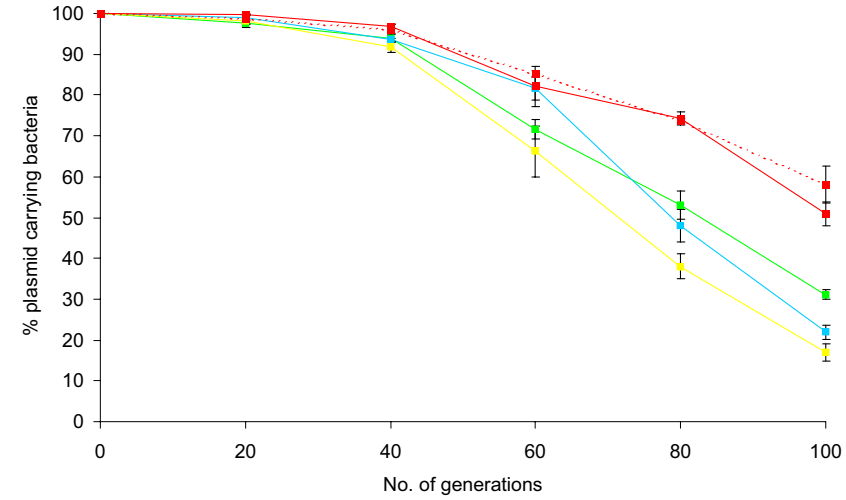

Figure 3

Stability of fluorescence-encoding plasmids. Segregational stability of plasmid pNT8 derivatives encoding the fluorescent proteins CFP (blue), GFP (green), YFP (yellow), DsRedExpress (red, solid line) or HcRed (red, broken line). L. monocytogenes harbouring the plasmids were propagated in $\mathrm{BHI}$ batch culture as described in the Methods section. Each point represents the average of data from three experiments. Error bars represent standard deviations.

eukaryotic cells, and is an optimal tool for comparative co-infection studies between up to three Listeria strains. However, for comparison of strains with highly different infection potentials, such as a wt Listeria and its inlA mutant, it should be taken into account that it is not pos-

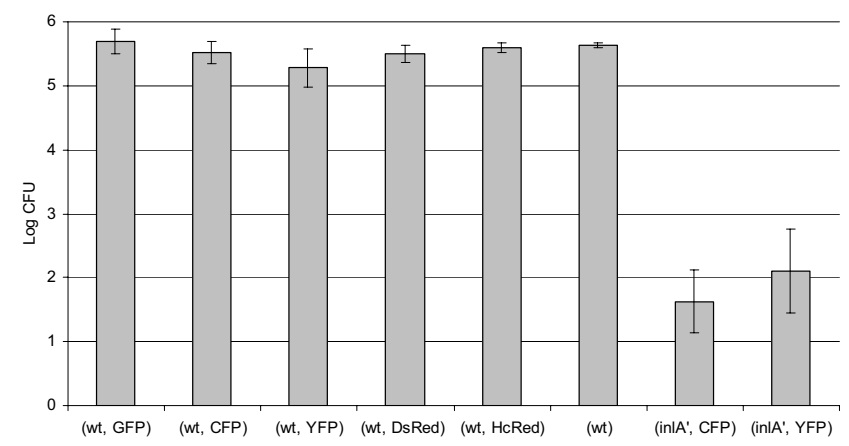

Figure 4

Invasion potentials fluorescence tagged $L$. monocytogenes. Numbers of Colony Forming Units (CFU) of fluorescent $L$. monocytogenes strains and its inlA' mutant, which were internalized per well of Caco- 2 cells. Counts were normalized to a concentration of $10^{7} \mathrm{~L}$. monocytogenes per $\mathrm{ml}$ in the bacterial cultures prior to infection of Caco- 2 cells. Each point represents the average of data from two experiments. Error bars represent standard deviations. Statistical analysis (Dunnet's test) confirmed that the infection potentials of the labelled strains were not different from that of the wt $(p<$ 0.05).
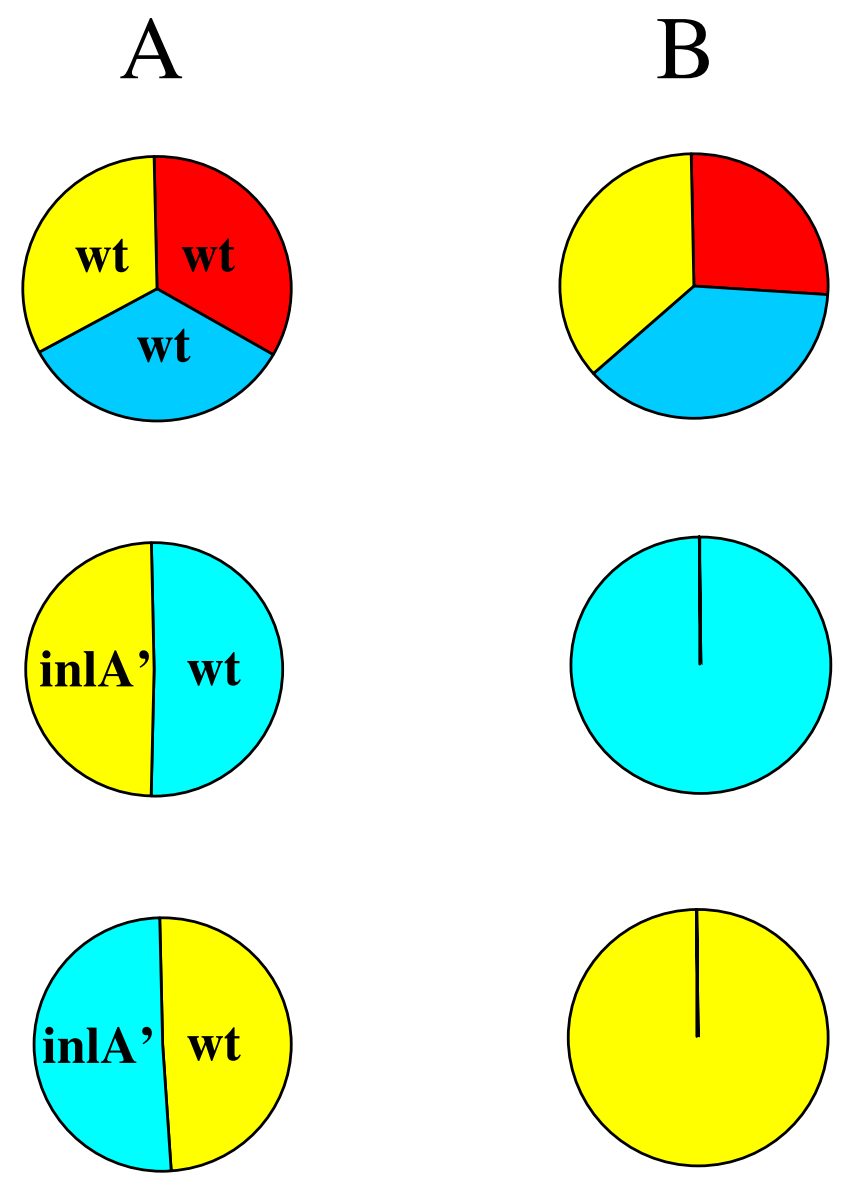

Figure 5

Mixed infections. Ratio of wt $L$. monocytogenes strains and its inIA' mutant tagged with YFP (yellow), DsRed (red) or CFP (blue) prior to invasion (A) and after recovery from Caco-2 cells (B).

sible to select for fluorescence, and that visualization of a strain constituting a very small minority might therefore be difficult. One solution to this would be to equip the less virulent strain with a distinct antibiotic resistance.

\section{Methods}

Bacterial strains, plasmids and growth media

Strains and plasmids used in this study are listed in Table 1. Bacterial strains were grown on BHI-agar supplemented with the relevant antibiotics. Erythromycin was used at a final concentration of 5 to $10 \mu \mathrm{g} / \mathrm{mL}$ for L. monocytogenes and of $150 \mathrm{ug} / \mathrm{mL}$ for $E$. coli. Nalidixic acid was used at a final concentration of $100 \mu \mathrm{g} / \mathrm{mL}$ for L. monocytogenes.

\section{DNA manipulation}

Standard techniques for DNA manipulation were applied [18]. Plasmid DNA was prepared using the QIAGEN mini spin prep Kit (QIAGEN, Germany) and chromosomal DNA was extracted by the QIAGEN Genomic DNA Tip 


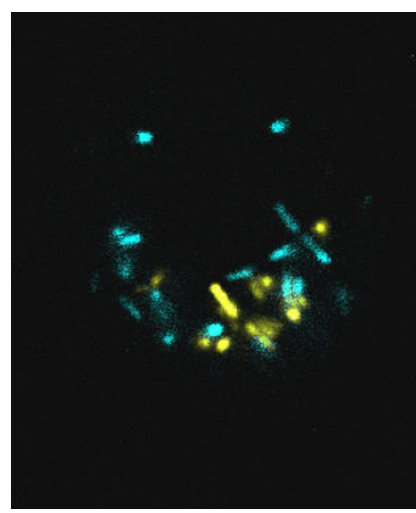

A

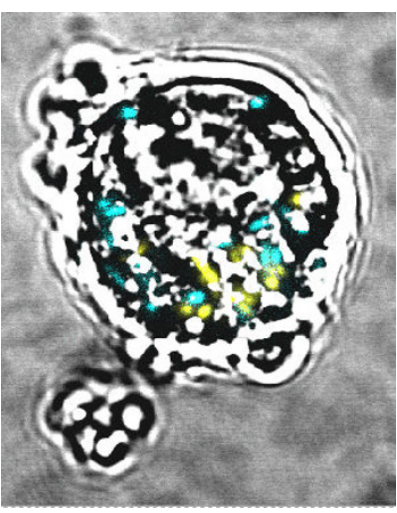

B

\section{Figure 6}

Visualization of internalized bacteria. Caco-2 cell containing a mixture of blue/cyan wt-CFP and yellow wt-YFP $L$. monocytogenes. A: Fluorescence microscopy image. B: Overlay of fluorescent image and phase contrast image showing the Caco- 2 cell.

100/G System (QIAGEN, Germany). Transformation of E. coli and $L$. monocytogenes was done by electroporation in a $0.2 \mathrm{~cm}$ cuvette by use of a GenePulser apparatus (Bio-Rad) set to $25 \mu \mathrm{F}, 400 \Omega$ and $2.5 \mathrm{kV} / \mathrm{cm}$. PCR was carried out using the Phusion High Fidelity PCR system (FINNZYMES OY, Finland). A GFX PCR DNA and Gel Band Purification Kit (Amersham Pharmacia Biotech) were applied for purification of DNA fragments.

\section{Construction of a multi colour tagging system}

Optimized version of the Cyan- and Yellow fluorescent proteins were created as follows: The hsp60 promoter driven GFP+ [19] was amplified and cloned into the pUC18 plasmid. pUC-yfp ${ }^{++}$was obtained by introducing the following mutations by site-directed mutagenesis (Stratagene): F46L, S65G, V68A, S72A, S175G, T203Y, whereas the pUC-cfp ${ }^{++}$, was obtained by introducing the K26R, Y66W, N146I, N164H, S175G, N212K mutations. Sequences can be found at [20]. The resulting proteins exhibit improved stability at elevated temperature (up to $46^{\circ} \mathrm{C}$ ) and stronger fluorescence as judged by comparison with commercially available variants.

To construct a multicolour tagging system, the $c f p^{++}$gene of pUC-cfp ${ }^{++}$, the $y f^{++}$gene of pUC-yfp ${ }^{++}$, the HcRed gene of pHcRed1 and the DsRed-Express gene of pDsRedExpress (Clontech Laboratories Inc., USA), were initially PCR amplified using either of the primersets Gfp_for/ Gfp_rev, HcRed_for/HcRed_rev, or RedEx_for/ DsRedEx_rev (Table 1). The four resulting PCR products encoding $c f p^{++}, y f p^{++}$, HcRed and DsRed-Express respectively, were restricted with BamHI and PstI and subse- quently ligated to the $7 \mathrm{~Kb}$ BamHI-PstI fragment of pNF8, to give pJEBAN2, pJEBAN3, pJEBAN4 and pJEBAN6. Finally, pJEBAN2, pJEBAN3, pJEBAN4, pJEBAN6 and pNF8 were electroporated into $E$. coli strain $S 17-\lambda$-pir to obtain donor strains from which pJEBAN2, pJEBAN3, pJEBAN4, pJEBAN6 and pNF8 can be conjugated into a broad range of bacteria by a simple 2 strain mating procedure.

\section{Fluorescent tagging of L. monocytogenes}

All matings were carried out using a slightly modified version of the protocol previously described by Trieu-Cout and coworkers [21]. Briefly, 250 uL culture of L. monocytogenes ScottA (recipient) cultivated for 18 hours at $37^{\circ} \mathrm{C}$ in BHI broth containing $100 \mu \mathrm{g} / \mathrm{mL}$ Nalidixic acid and $250 \mu \mathrm{L}$ culture of S17- $\lambda$-pir harbouring pJEBAN2 (donor) cultivated for 18 hours at $37^{\circ} \mathrm{C}$ in BHI broth containing $150 \mu \mathrm{g} / \mathrm{mL}$ erythromycin was harvested by centrifugation, washed twice with $250 \mu \mathrm{L}$ of $0.9 \% \mathrm{NaCl}$ to remove antibiotics and subsequently resuspended in $25 \mu \mathrm{L}$ of $0.9 \%$ $\mathrm{NaCl}$. The $25 \mu \mathrm{L}$ aliquots of the donor and the recipient were mixed and subsequently spotted onto a BHI-agar plate containing $0.5 \mu \mathrm{g} / \mathrm{mL}$ penicillinG. Following 24 hours of incubation at $37^{\circ} \mathrm{C}$, the resulting conjugation spots were gently removed from the BHI-agar plate and resuspended in $1 \mathrm{~mL} 0.9 \% \mathrm{NaCl}$. Finally, in order to select Cyan fluorescent transconjugants (strains harbouring pJEBAN2), appropiate dilutions of the conjugation mix were spread onto BHI-agar containing $100 \mu \mathrm{g} / \mathrm{mL}$ nalidixic acid and $10 \mu \mathrm{g} / \mathrm{mL}$ erythromycin. By analogy, pNF8, pJEBAN3, pJEBAN4 and pJEBAN6 were conjugated from S17- $\lambda$-pir into $L$. monocytogenes to give green fluorescent, yellow fluorescent and red fluorescent strains. The inlA' mutant of L. monocytogenes (construction described below) was tagged with pJEBAN2 and pJEBAN3 in a similar way.

\section{Plasmid stability in vitro}

To obtain starter cultures in which the entire L. monocytogenes populations carried pNF8, pJEBAN2, pJEBAN3, pJEBAN4 or pJEBAN6, brightly fluorescent single colonies of the strain harbouring either of these plasmids were initially inoculated into $10 \mathrm{~mL}$ BHI supplemented with 100 $\mu \mathrm{g} / \mathrm{mL}$ Nalidixic acid and $10 \mu \mathrm{g} / \mathrm{mL}$ Erythromycin and incubated at $37^{\circ} \mathrm{C}$ for 18 hours. At timepoint $\mathrm{g}=0$ (number of population generations in the absence of selective pressure), $10 \mu \mathrm{l}$ of each of the starter cultures were inoculated into $10 \mathrm{~mL} \mathrm{BHI}$ supplemented with 100 $\mu \mathrm{g} / \mathrm{mL}$ of Nalidixic acid (non selective media) and from the resulting cultures, samples were immediately taken to determine the fraction of plasmid harbouring bacteria at the start of the experiment $(g=0)$. Following 12 hours of growth in the absence of selective pressure (time point $\mathrm{g}=$ 10), $10 \mathrm{uL}$ of each of the outgrown cultures were again inoculated into $10 \mathrm{~mL}$ of fresh medium, and from the 
resulting cultures samples were taken to determine the fraction of fluorescent bacteria (plasmid harbouring bacteria) at timepoint $g=10$. This procedure was repeated every 12 hours for a total of 120 hours equivalent to approximately 100 generations. Following 24 hours of incubation at $37^{\circ} \mathrm{C}$, all $\mathrm{BHI}$-agar plates were replicated to BHI-agar plates supplemented with $10 \mu \mathrm{g} / \mathrm{ml}$ of Erythromycin, and the fraction of plasmid harbouring bacteria was determined as the number of Erythromycin resistant colonies divided by the total number of colonies present on the BHI-agar master plate. It was verified that all Erythromycin-resistant colonies were fluorescent by inspection on a UV-table (exitation $302 \mathrm{~nm}$ ). All sampling was done in duplicates. The experiment was repeated 3 times.

\section{Construction of an L. monocytogenes deletion mutant designated inIA'}

A mutant of L. monocytogenes ScottA carrying an in-frame deletion of the last 771 bp of the inlA gene was constructed using 2-way splicing by overlap extension (SOE) PCR [22] followed by allelic exchange mutagenesis. Initially, 2 PCR fragments designated InlA-int (293 bp) and InlA-down (270 bp) covering different regions of the inlA gene was amplified from chromosomal DNA of L. monocytogenes by use of the primersets, InlA_N_up/ InlA_N_down and InlA_C_up/InlA_C_down, respectively (Table 2). Since the inlA gene of L. monocytogenes ScottA had only been partially sequenced at the time of design, primers were designed based on the genome sequence of L. monocytogenes 4b 2365 [23]. In a second round of PCR, fragments InlA-int and InlA-down were spliced together by use of the primerset InlA_N_up/InlA_C_down to produce a 538 bp fragment (designated InlA') covering nt 1381 to nt 1630 directly followed by nt 2401 to nt 2652 of inlA. The PCR fragment InlA' was restricted with BamHI and HindIII, and cloned in between the BamHI and HindIII sites of the temperature sensitive shuttle vector pAULA [24]. The resulting plasmid pJEBAN12 was introduced into L. monocytogenes by electroporation and inlA mutants carrying inframe deletions covering the last $771 \mathrm{nt}$ of the inlA gene were subsequently constructed as previously described [25]. Finally, strains carrying the desired deletion were identified by PCR, and the correct deletion event was verified by DNA sequence analysis of the resulting PCR product.

\section{Caco-2 invasion assays}

Enterocyte-like Caco-2 cells were cultivated and prepared as previously described [3]. Bacteria were cultivated over night at $37^{\circ} \mathrm{C}$ in BHI media supplemented with $10 \mu \mathrm{g} / \mathrm{mL}$ of Erythromycin and diluted to a concentration of $10^{7}$ bacteria/mL prior to the invasion assays. For co-invasion assays, the two or three strains were mixed in a $1: 1$ or $1: 1: 1$ ratio. One $\mathrm{ml}$ of bacterial culture was applied to each well, resulting in a multiplicity of infection of approximately 25 bacteria per Caco- 2 cell. Following 1 hour of invasion and 2 hours of gentamycin treatment to kill extracellularly located bacteria, Caco- 2 cells were lysed, diluted and subsequently spread onto BHI-agar supplemented with 10 $\mu \mathrm{g} / \mathrm{mL}$ of Erythromycin. After 96 hours of incubation at $22^{\circ} \mathrm{C}$, plates were placed on a UV table (excitation at 302 $\mathrm{nm})$, fluorescent colonies were enumerated, and digital images were recorded as described below. Sampling was done in triplicate, and the experiments were performed twice.

Table 2: Primers designed in this study.

\begin{tabular}{ll}
\hline Primer & Sequence \\
\hline Gfp_for & 5'-ATATAGGATCCGAAAGGAGGTTTATTAAAATGGCTAGCAAAGGAGAAGAACTTT-3' \\
& BamHI \\
Gfp_rev & 5'-TTTTTCTGCAGTTATTTGTAGAGCTCATCCATGCC-3' \\
& Pstl \\
HcRed_for & 5'-ATATAGGATCCGAAAGGAGGTTTATTAAAATGGTGAGCGGCCTGCTGAAGG-3' \\
& BamHI \\
HcRed_rev & 5'-TTTTTCTGCAGTTAGTTGGCCTTCTCGGGCAGGTC-3' \\
& Pstl \\
DsRedEx_for & 5'-ATATAGGATCCGAAAGGAGGTTTATTAAAATGGCCTCCTCCGAGGACGTC-3' \\
& BamHI \\
DsRedEx_rev & 5'-TTTTTCTGCAGTTACAGGAACAGGTGGTGGSGG-3' \\
& PstI \\
InIA_N_up & 5'-ATATAGGATCCGCGGCCGCGAATTTACCTAGTTATACCAATGAAGT-3' \\
& BamHI Notl \\
InIA_N_down & 5'-CATCTAGCTCTTTACACTACTTCTAAGTTCCGCCGGTTTGGGCATC-3' \\
InIA_C_up & 5'-TAGAAGTAGTGTAAAGAGCTAGATG-3' \\
InIA_C_down & 5'-ATATAAAGCTTGCGGCCGCTTCTGCAAAAGCATCATCTGGAAAA-3' \\
& HindIII NotI \\
\hline
\end{tabular}

Underlined areas mark targets for the indicated restriction enzymes. 


\section{Fluorescence microscopy}

Fluorescence microscopy was carried out by use of a Leitz DM RBE microscope fitted with filter cubes $G / R, I 3$ and N2.1 (Leica Microsystems Heidelberg GmbH, Germany).

Microscopic observations and image acquisitions were performed with a model TCS SP1 three channel scanning confocal laser microscope (Leica Microsystems Heidelberg GmbH, Germany) equipped with an argon laser (458 $\mathrm{nm}, 476 \mathrm{~nm}, 488 \mathrm{~nm}$ and $514 \mathrm{~nm}$ wavelength) and two HeNe lasers (543 nm and $633 \mathrm{~nm}$ wavelength) and a variable spectrophometric detection system. The Leica Confocal Sofware TCS SP/NT version 2.5.1347 was used.

\section{Authors' contributions}

JBA and ABL carried out the molecular constructions. JBA carried out the invasion assays and BBR did the microscopy. BBC and TRL conceived of the study and participated in its design and coordination. JBA and TRL drafted the manuscript. All authors red and approved the final manuscript.

\section{Acknowledgements}

The authors thank Grethe Fisher and Mansour Badaki for excellent technical assistance. The Danish Research Council supported this work.

\section{References}

I. Farber JM, Peterkin PI: Listeria monocytogenes, a food-borne pathogen. Microbiol Rev 199I, 55:476-5II.

2. Low JC, Donachie W: A review of Listeria monocytogenes and listeriosis. Vet J 1997, 153:9-29.

3. Larsen CN, Norrung B, Sommer HM, Jakobsen M: In Vitro and In Vivo Invasiveness of Different Pulsed-Field Gel Electrophoresis Types of Listeria monocytogenes. Appl Environ Microbiol 2002, 68:5698-5703.

4. Wiedmann M, Bruce JL, Keating C, Johnson AE, McDonough PL, Batt $C A$ : Ribotypes and virulence gene polymorphisms suggest three distinct Listeria monocytogenes lineages with differences in pathogenic potential. Infect Immun 1997, 65:2707-27I6.

5. Kim H, Boor KJ, Marquis H: Listeria monocytogenes \{sigma\}B Contributes to Invasion of Human Intestinal Epithelial Cells. Infect Immun 2004, 72:7374-7378.

6. Gaillard JL, Finlay BB: Effect of cell polarization and differentiation on entry of Listeria monocytogenes into the enterocytelike Caco-2 cell line. Infect Immun 1996, 64:1299-1308.

7. Sleator RD, Wemekamp-Kamphuis HH, Gahan CGM, Abee T, Hill C: A PrfA-regulated bile exclusion system (BilE) is a novel virulence factor in $<i>$ Listeria monocytogenes $</ i>$. Molecular Microbiology 2005, 55: I 183-I 95 [http://www.blackwell-synergy.com/ links/doi/l0.1III/j.1365-2958.2004.04454.x/abs].

8. Valdivia RH, Hromockyj AE, Monack D, Ramakrishnan L, Falkow S: Applications for green fluorescent protein (GFP) in the study of host-pathogen interactions. Gene 1996, 173:47-52.

9. Lun S, Willson PJ: Expression of green fluorescent protein and its application in pathogenesis studies of serotype 2 Streptococcus suis. J Microbiol Methods 2004, 56:40I-4I2.

10. Fortineau N, Trieu-Cuot P, Gaillot O, Pellegrini E, Berche P, Gaillard $\mathrm{JL}$ : Optimization of green fluorescent protein expression vectors for in vitro and in vivo detection of Listeria monocytogenes. Research in Microbiology 2000, I 5 I:353-360.

II. Pentecost M, Otto G, Theriot JA, Amieva MR: Listeria monocytogenes Invades the Epithelial Junctions at Sites of Cell Extrusion. PLoS Pathog 2006, 2:e3.

12. Prasher DC, Eckenrode VK, Ward WW, Prendergast FG, Cormier MJ: Primary structure of the Aequorea victoria green-fluorescent protein. Gene 1992, I I I:229-233.
13. Gurskaya NG, Fradkov AF, Terskikh A, Matz MV, Labas YA, Martynov VI, Yanushevich YG, Lukyanov KA, Lukyanov SA: GFP-like chromoproteins as a source of far-red fluorescent proteins. FEBS Lett 200I, 507:16-20.

14. Baird GS, Zacharias DA, Tsien RY: Biochemistry, mutagenesis, and oligomerization of DsRed, a red fluorescent protein from coral. Proc Natl Acad Sci U S A 2000, 97: I I 984-I 1989.

15. Gaillard JL, Berche P, Frehel C, Gouin E, Cossart P: Entry of L. monocytogenes into cells is mediated by internalin, a repeat protein reminiscent of surface antigens from gram-positive cocci. Cell |99|, 65: I|27-I|4I.

16. Olier M, Garmyn D, Rousseaux S, Lemaitre JP, Piveteau P, Guzzo J: Truncated Internalin A and Asymptomatic Listeria monocytogenes Carriage: In Vivo Investigation by Allelic Exchange. Infect Immun 2005, 73:644-648.

17. Cossart P, Pizarro-Cerda J, Lecuit M: Invasion of mammalian cells by Listeria monocytogenes: functional mimicry to subvert cellular functions. Trends Cell Biol 2003, 13:23-3 I.

18. Sambrook J, Fritsch EF, Maniatis T: Molecular Cloning - A Laboratory Manual 2nd edition. Cold Spring Harbor Laboratory Press; 1989.

19. Scholz O, Thiel A, Hillen W, Niederweis M: Quantitative analysis of gene expression with an improved green fluorescent protein. p6. Eur J Biochem 2000, 267:1565-I570.

20. TaMaRa's staff website 2006 [http://www.necker.fr/tamara/pages/ ariel.html].

21. Trieu-Cuot P, Derlot E, Courvalin P: Enhanced conjugative transfer of plasmid DNA from Escherichia coli to Staphylococcus aureus and Listeria monocytogenes. FEMS Microbiol Lett 1993, 109:19-23.

22. Horton RM, Cai ZL, Ho SN, Pease LR: Gene splicing by overlap extension: tailor-made genes using the polymerase chain reaction. Biotechniques 1990, 8:528-535.

23. Nelson KE, Fouts DE, Mongodin EF, Ravel J, DeBoy RT, Kolonay JF, Rasko DA, Angiuoli SV, Gill SR, Paulsen IT, Peterson J, White O, Nelson WC, Nierman W, Beanan MJ, Brinkac LM, Daugherty SC, Dodson RJ, Durkin AS, Madupu R, Haft DH, Selengut J, Van Aken S, Khouri H, Fedorova N, Forberger $\mathrm{H}$, Tran B, Kathariou S, Wonderling LD, Uhlich GA, Bayles DO, Luchansky JB, Fraser CM: Whole genome comparisons of serotype $4 b$ and $1 / 2 a$ strains of the foodborne pathogen Listeria monocytogenes reveal new insights into the core genome components of this species. Nucl Acids Res 2004, 32:2386-2395.

24. Chakraborty T, Leimeister-Wachter M, Domann E, Hartl M, Goebel W, Nichterlein T, Notermans S: Coordinate regulation of virulence genes in Listeria monocytogenes requires the product of the prfA gene. J Bacteriol 1992, 174:568-574.

25. Guzman CA, Rohde M, Chakraborty T, Domann E, Hudel M, Wehland J, Timmis KN: Interaction of Listeria monocytogenes with mouse dendritic cells. Infect Immun 1995, 63:3665-3673.

26. de LV, Timmis KN: Analysis and construction of stable phenotypes in gram-negative bacteria with Tn5- and Tn I0-derived minitransposons. Methods Enzymol 1994, 235:386-405.

27. Yanisch-Perron C, Vieira J, Messing J: Improved MI3 phage cloning vectors and host strains: nucleotide sequences of the MI3mpI 8 and pUC 19 vectors. Gene 1985, 33:103-119.

28. Glaser P, Frangeul L, Buchrieser C, Rusniok C, Amend A, Baquero F, Berche P, Bloecker H, Brandt P, Chakraborty T, Charbit A, Chetouani F, Couve E, de Daruvar A, Dehoux P, Domann E, Dominguez-Bernal G, Duchaud E, Durant L, Dussurget O, Entian KD, Fsihi H, Portillo FGD, Garrido P, Gautier L, Goebel W, Gomez-Lopez N, Hain T, Hauf J, Jackson D, Jones LM, Kaerst U, Kreft J, Kuhn M, Kunst F, Kurapkat G, Madueno E, Maitournam A, Vicente JM, Ng E, Nedjari H, Nordsiek G, Novella S, de Pablos B, Perez-Diaz JC, Purcell R, Remmel B, Rose M, Schlueter T, Simoes N, Tierrez A, Vazquez-Boland JA, Voss H, Wehland J, Cossart P: Comparative Genomics of Listeria Species. Science 200I, 294:849-852

29. Vicente MF, Baquero F, Perez-Diaz JC: Cloning and expression of the Listeria monocytogenes haemolysin in Escherichia coli. FEMS Microbiology Letters 1985, 30:77-79.

30. Olier M, Pierre F, Lemaitre JP, Divies C, Rousset A, Guzzo J: Assessment of the pathogenic potential of two Listeria monocytogenes human faecal carriage isolates. Microbiology 2002, |48: |855-|862. 